EVS25

Shenzhen, China, Nov 5-9, 2010

\title{
Research of the hybrid power train dynamic test system
}

\author{
Zheng $\mathrm{Li}^{1}$, Yuanfa Deng ${ }^{1}$, Jixin Xin ${ }^{2}$, Xianling Xiong ${ }^{2}$, Pingxing $\mathrm{Xu}^{1}$, Zhaoming $\mathrm{Li}^{1}$, Wanhu ${ }^{1}$ Jin \\ ${ }^{1}$ Dongfeng Motor Corporation Technical Center., No.663, Zhushanhu Road, Wuhan, Hubei, 430058, China \\ ${ }^{2}$ Dongfeng Electric Vehicle Co.Ltd, No. 538, Dongfeng Road, Wuhan, Hubei, 430056, China
}

\begin{abstract}
Based on the technology of conventional engine dynamic test system, using high dynamic AC frequency conversion dynamometer, developing of the simulators of road load, vehicle inertia, driver etc., a heavy duty hybrid power train dynamic test stand is developed. The stand can supply a near real road environment for hybrid power train of the vehicle. The R\&D of different coupling structure of hybrid power train can be executed in the test system. All kinds of vehicle performance tests including power performance tests, energy economy tests, special hybrid function tests etc. can be implemented in it. The developed hybrid power train dynamic test system is a useful tool for developing the key technology of hybrid electric bus.

Keywords : hybrid electric vehicle (HEV), power train, dynamic test system, test bench, test facility
\end{abstract}

\section{General}

Lots of matching / calibration/ verification work is needed in the course of developing hybrid power train. But, the developing method is not enough, many companies only have components test facilities, like engine test bench/ electric motor test bench/ battery test bench, even some companies buy conventional power train test facilities, special hybrid research can't be executed, such as regenerative brake power test etc... Most of the developing works such as matching, calibration, VCU development can only be implemented in chassis dynamometer or road using whole vehicle. This kind of situation influences the quality of product, extends the period of development.

The developed hybrid power train test facility can both commit functions of conventional power train test bench and develop specialized research of HEV. The new test bench can develop VCU (control unit of hybrid electric vehicle), execute vehicle performance tests and special tests only use hybrid power train without the whole vehicle.

\section{Scheme of hybrid power train}




\section{dynamic test system}

\subsection{Configuration of power train of the hybrid electric vehicle}

Using parallel hybrid power train as an example in figure 1 , the new power train adds $\mathrm{VCU}$ (vehicle control unit), electric motor\& MCU (motor control unit), battery \& BMS (battery management system) etc. which are specially used in hybrid electric vehicles and different from conventional power train. The hardcore of the hybrid power train is the VCU; it is the brain of the vehicle. VCU will harmonize and cooperate with other components controllers, to realize the calculating of the requirement of the driver using the signals of acceleration pedal, brake pedal, gear, vehicle speed etc., distributing the certain demand between the engine and the motor and controlling the certain parts using CAN technology. Engine and motor are coupled up through gearbox; gearshift is controlled by AMT controller; engine is controlled by ECM (engine control management), motor is controlled by $\mathrm{MCU}$, battery using is controlled by BMS.

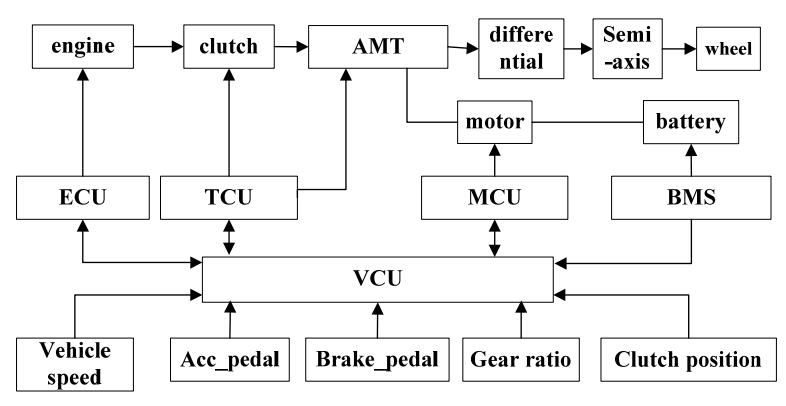

Figure 1: Configuration of a parallel hybrid system

\subsection{Architecture of the test system}

Considering the key technology of developing a hybrid system is the development of hybrid power train, especially the VCU, we shorten the power line, cancel the main reducer, semi axles and wheels etc., and we use one dynamometer to simulate the real road resistance and vehicle inertia. That is, engine dynamic test bench, road load simulator and mode control system are combined together to contribute a hybrid power train test facility. Figure 2 shows the components of a typical hybrid power train test.

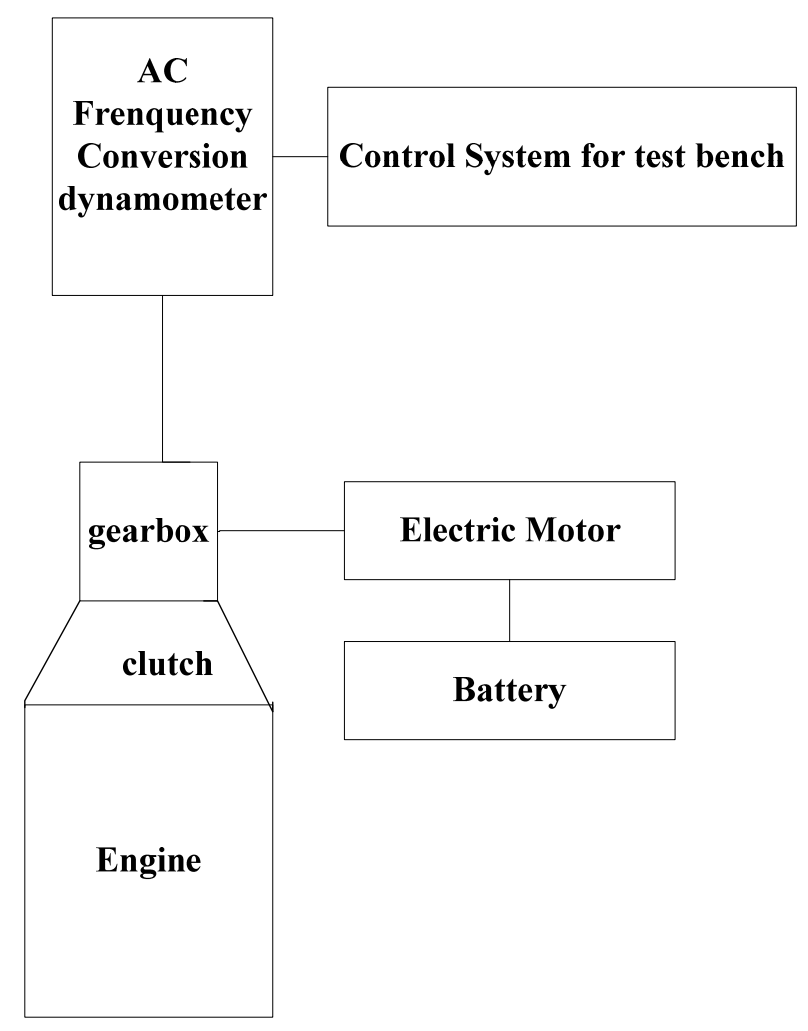

Figure 2: Architecture of the hybrid power train test

\subsection{Configuration of the test facility}

The test facility as shown in figure 3 consists of an $\mathrm{AC}$ frequency conversion dynamometer, manager of bench control \& detection center, dynamic simulator, test mode controller, simulator of driver, data collection system, and test condition control system etc. 


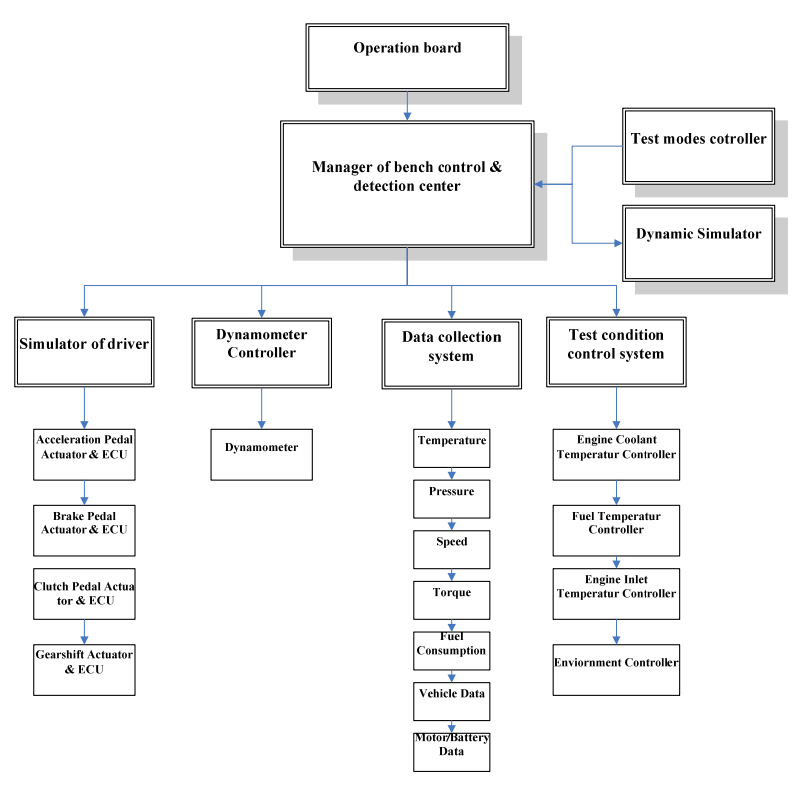

Figure 3: Configuration of the test facility

\section{Theory of the test system}

The new developed hybrid power train dynamic test system is developed based on conventional test bench; we only introduce some special functions different from the routine ones, such as dynamic simulation system, simulator of driver, test mode controller, etc...

\subsection{Dynamometer}

For the static experiments, dynamometer executes the function of absorbing the power from \& outputting the power to the hybrid power train. For our test facility, dynamometer not only simulates the inertia and road resistance of the vehicle, but also simulates the brake force in the deceleration period, so we choose an AC frequency conversion dynamometer with lower inertia and higher dynamic response.

\subsection{Dynamic Simulator}

According to Auto Theory, the road resistance consists of rolling resistance, wind resistance, gradient resistance and speedup force (or slowdown force), the relationship between the propel force and road resistance is as following:

$$
\begin{aligned}
\mathrm{F}_{\mathrm{t}} & =\mathrm{F}_{\mathrm{f}}+\mathrm{F}_{\mathrm{w}}+\mathrm{F}_{\mathrm{i}}+\mathrm{F}_{\mathrm{j}} \\
& =\mathrm{G} \cos \alpha+\frac{\mathrm{C}_{\mathrm{D}} \mathrm{A}}{21.15} \mathrm{U}_{\mathrm{a}}{ }^{2}+\mathrm{G} \sin \alpha+\delta m \frac{\mathrm{d} \mathrm{U}_{\mathrm{a}}}{\mathrm{dt}}
\end{aligned}
$$

There into:

$\mathrm{F}_{\mathrm{t}}$ : propel force;

$\mathrm{F}_{\mathrm{f}}$ : rolling resistance;

$\mathrm{F}_{\mathrm{w}}$ : wind resistance;

$\mathrm{F}_{\mathrm{i}}$ : the gradient resistance;

$\mathrm{F}_{\mathrm{j}}$ : the speedup force \& deceleration force;

$\mathrm{G}=\mathrm{mg}$ : vehicle gravity;

m: vehicle mass;

$\mathrm{f}$ : rolling resistance factor;

$\alpha$ : the gradient angle;

$\mathrm{C}_{\mathrm{D} \text { : the wind resistance factor; }}$

A: windward area;

$\mathrm{U}_{\mathrm{a}}$ : vehicle speed;

$\delta$ : conversion factor of rolling mass;

$\frac{\mathrm{dU}_{\mathrm{a}}}{\mathrm{dt}}$ : the acceleration or deceleration of the vehicle;

In our test system, the total road resistance is simulated by dynamometer, that is:

$$
\mathrm{F}_{\mathrm{t}}=\mathrm{F}_{\mathrm{D}}
$$

There into:

$\mathrm{F}_{\mathrm{D}}$ : the road resistance simulated by dynamometer

Dynamic simulator consists of computer and certain simulation software. The test bench uses real time torque control method; torque is calculated from formula 1. First, using the parameters such as vehicle mass, rolling mass conversion factor, rolling resistance factor, wind area $\&$ wind resistance factor, gradient angle, relative wind speed, gear ratio \& final drive ratio, wheel radius etc., and according to the 
real time measured vehicle speed and torque from dynamometer, the simulator software could calculate the real time roll resistance, wind resistance, gradient resistance \& speedup force (or slowdown force), the sum of the four resistances contributes the theoretic total road resistance which should be simulated by the dynamometer; then the calculated road resistance will be sent to dynamometer controller, and it will control the dynamometer to output the real time road resistance to make the power train work just like in the road.

\subsection{Simulator of driver}

Simulator of driver consists of acceleration pedal actuator and controller (ACC pedal), clutch pedal actuator and controller (Clu pedal), gear shifting actuator and controller (Gear handler), brake pedal actuator and controller (Brk pedal), and driver function controller.

Driver mode controller consists of different modules representing different driving behaviors. For an example, we can choose ECO driving mode, which means that the driver will shift the gear at lower engine speed and push the Acc pedal softer.

According to the chosen driving behavior, first the simulation software will use certain driving module and certain driving messages to calculate the target pedal positions and target gear position; second the controller will send the control targets to the control systems; and then the control system will direct the certain actuators to behave like a real driver.

The real time data will also be transferred to the main computer and VCU, the main computer will harmonize all other control systems in the test bench, and VCU will use these messages to implement the control of the vehicle and realize the driving cycle simulation.

Using the simulator of driver and $\mathrm{VCU}$, the test facility could simulate different behaviors of drive away, speedup, slow down, coast down\& cruise etc... Figure 4 describes the configuration of simulator of driver

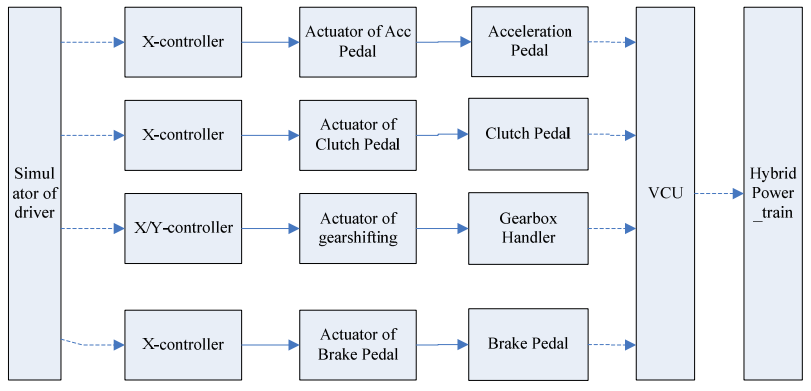

Figure 4: Configuration of simulator of driver

\subsection{Test mode controller}

Test mode controller is one of the sub-systems of the manager of test bench, it defines the test project. It consists of the close loop test which is used in different driving cycle simulation defined by the customer, and the open loop test which is used in different pedal performance tests defined by the customer, etc...

Close loop test aims at a given driving cycle. According to the comparison between the actual vehicle speed and target vehicle speed, using the chosen driver's behavior, the simulator of driver could calculate the target pedal position and target gear ratio. Using pedal actuators, test facility could control the pedals and gear to reach the target positions. VCU and TCU could sample the messages of the sensors and realize the control of the power train, to realize the simulation of the driving cycle. Close loop test normally is used to develop control strategies of hybrid vehicles aiming at better fuel consumption at a certain driving cycle.

Open loop test mainly uses a preset pedal position and gear position to start the test, such as full load acceleration test and deceleration performance test. Open loop test mainly used to develop power performance and regenerated (or brake) power performance.

\subsection{Data collection system}

Data collection system includes various sensors, AD modules, modules of analog input $\&$ output, modules of digital input \& output and special function instruments and so on. In order to make better reproducing of the control of the vehicle and the 
performance of the vehicle using this power train test bench, high sample frequency is occupied.

The parameters colleted not only include all kinds of conventional ones such as temperatures, pressures, speeds, torques, fuel consumption and so on, but also include special used battery voltages, currents, pedal positions etc., and include some vehicle data like vehicle speed, distance, brake distance \& gear ratio etc. too.

\section{Functions and validations}

\subsection{Functions}

In the test bench, we can preset different kinds of vehicle and components \& road messages etc. to realize the control of the certain vehicle in the certain environment. We can preset road information, such as gradient, rolling resistance, wind velocity etc.; we can preset vehicle specification, such as vehicle mass, rolling radius, wind area, final ratio and so on; we can preset characteristics of some components such as clutch specification, gearshift characteristics etc.; we can preset test environment, such as temperature, pressure, humidity and so on; we could preset the messages we are interested in, and all these messages could be measured and recorded in the data collection system.

The test bench could not only implement all the experiments of conventional engine performance, but also execute the following development tests of hybrid power train:

- Implement joint debugging and testing of hybrid power train including VCU, engine and ECU, AMT and TCU, electric motor and MCU, battery and BMS etc.

- Implement optimization of the performance of the hybrid power train.

- Implement research development \& optimization of the control strategies of energy management \&regenerated brake

- Implement power performance tests of vehicle
- Implement brake performance tests of vehicle

- Implement energy consumption tests using different driving cycles such as Chinese typical city bus cycle, American UDDS cycle etc., and other customer designed driving cycles

- $\quad \mathrm{R} \& D$ control strategies of gear shifting and actuators of AMT \& AT

- Implement electric motor performance tests

\subsection{Validations}

Validation test is very important for demonstrating the acceptance of the functions of the test facility. We supply some typical test to show the results.

\subsubsection{Coast down test}

Coast down test shows the inertia simulation accuracy of the test bench. Figure 5 and Table 1 shows the result.

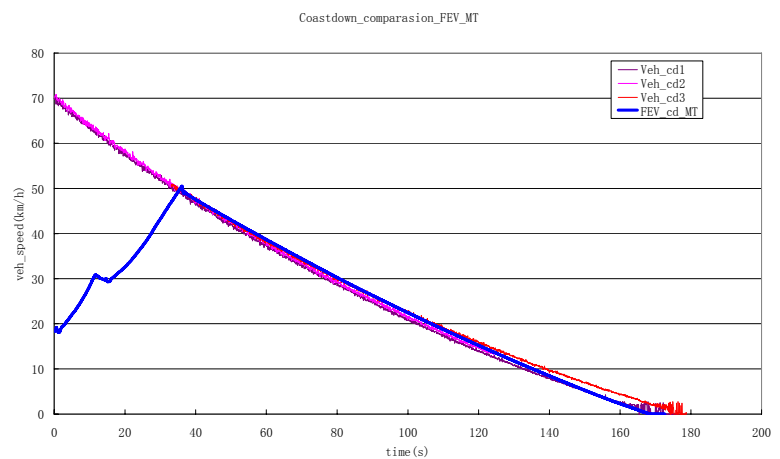

Figure 5. Coast down test

Table 1. Comparison between the test bench result and the real road test result

\begin{tabular}{|c|c|c|c|c|}
\hline & & $\begin{array}{c}50 \mathrm{~km} / \mathrm{h} \\
\text { to } 0\end{array}$ & average & $\begin{array}{c}\text { Relative } \\
\text { error } \\
(\%)\end{array}$ \\
\hline \multirow{2}{*}{$\begin{array}{c}\text { Road } \\
\text { Test }\end{array}$} & Test 1 & $823.5 \mathrm{~m}$ & \multirow{2}{*}{$848.5 \mathrm{~m}$} & \multirow{2}{*}{-} \\
\hline & Test 2 & $873.5 \mathrm{~m}$ & & \\
\hline $\begin{array}{c}\text { Power } \\
\text { train } \\
\text { Test }\end{array}$ & Test 1 & $844 \mathrm{~m}$ & $844 \mathrm{~m}$ & $-0.5 \%$ \\
\hline
\end{tabular}


The results shows that test bench result is quite close to the real vehicle test results, it shows that the inertia simulation of the test bench is valid.

\subsubsection{Open loop test}

Power performance test is very important for vehicle, and it's especially important to show the difference of the hybrid power train and conventional power train. Regenerated power performance test is one of the most important test, it concerns to the electric brake performance and influences vehicle fuel consumption greatly.

Open loop test mainly uses a preset pedal position and gear position to start the test, such as full load acceleration test and deceleration performance test. Open loop test mainly used to develop power performance and regenerated (or brake) power performance. Figure 6 shows the test results.

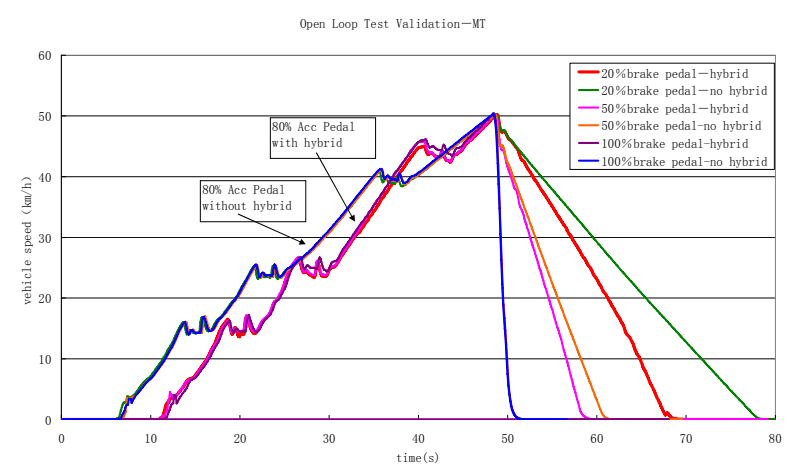

Figure 6. Acceleration Test \& Brake Test

According to the acceleration tests, we can also see that the test bench could reproduce the test results. This demonstrates the reproducing characteristics. According to the characteristic curves, we can see that, in the same acceleration pedals position, hybrid power train will get higher acceleration; and for the same brake pedal positions, hybrid power train will get higher deceleration too; in $100 \%$ brake pedal position, electric brake torque is much smaller than mechanical brake torque...This test validates the open loop function of brake performance of the test bench.

\subsubsection{Close loop test}

Figure 8 shows the close loop test cycle simulation result.

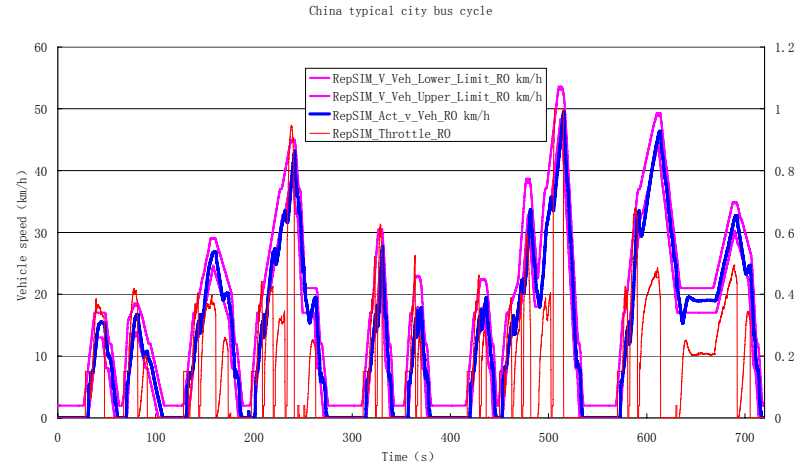

Figure 8 . Chinese typical city bus cycle

From the results, we can see that the test bench could simulate the vehicle driving very well; it could follow the target vehicle speed closely. And we could get other message as we need. This test validates the close loop function of the best bench.

\section{Conclusion}

The new developed test facility could use hybrid power train to execute vehicle road performance test (or dynamometer test).

Simulator of driver could use pedal actuators to simulate a real vehicle drive, to eliminate the different drive behavior, and to achieve accuracy control and good repeatability compared with road test.

Test condition control system could control the fuel temperature, cooling system temperature, environment temperature etc., this will help to achieve better repeatability, better comparison and clear conclusion compared with road test.

Compared with road test, we can use some expensive data acquisition instruments and analyzer instruments which are hard to be installed in the road vehicle to get much more performance messages in the test bench, to improve the research ability.

In the former period of a new hybrid system development, a flexible combination of available components could be organized into different coupling architectures, we can use the architecture and the simulation model and some useful tools to construct a rapid prototyping Environment for 
developing a propulsion control unit for a hybrid vehicle to shorten development period.

The new developed hybrid power train test bench is a useful tools helping shorten development period, raise development quality and save money, and worth to be popularized.

\section{Reference}

【1】Zhisheng Yu, Automobile Theory, Third Edition, Oct. 2010.

【2】Jixin Xin, Yu Zhu, Yongge Luo, Pingxing Xu, The Key Technique for Developing Hybrid Electric Vehicles in DongFeng Motor Corporation, The Symposium of the Fourth Conference of International Clean Vehicle Development of Beijing, Nov. 2005

【3】 Nan Lin, Yuanfa Deng, Xianling Xiong,Report of the Feasibility of Developing a Dynamic Power Train Test Facility using for Heavy Duty Hybrid Electric Vehicle Development, Jan. 2005.

\section{Author}

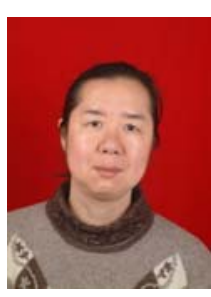

\section{Zheng Li, Professor Engineer}

Responsible for hybrid electric vehicle VCU(vehicle control unit) software development. Responsible for function definition of the test bench and bench function confirmation.

\section{Yuanfa Deng, Senior Engineer}

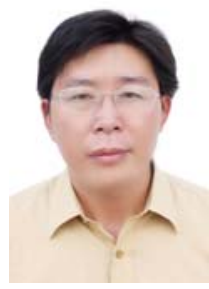

Responsible for test bench configuration scheme confirmation \& function definition. Responsible for installation \& commission support and acceptance execution.

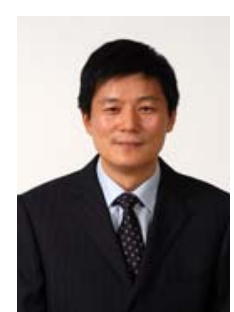

\section{Jixin Xin, Professor Engineer}

Responsible for electric vehicle development of the company. Responsible for test facility general target determination and resources assurance.

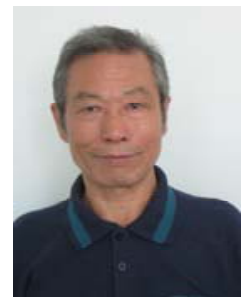

\section{Xianling Xiong, Professor Engineer}

Responsible for test capacity planning of the company. Responsible for test bench pre-investigation \& test facility configuration scheme bring forward.

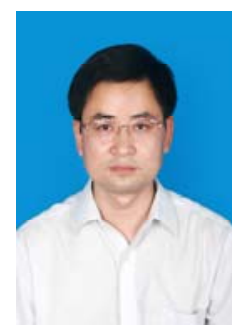

\section{Pingxing Xu, Senior Engineer}

Responsible for hybrid electric bus development. Responsible for test facility technical scheme determination, responsible for project development time schedule achievement..

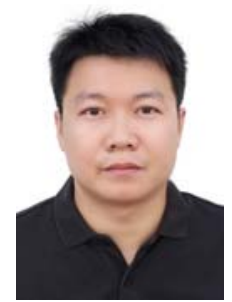

\section{Zhaoming Li, Engineer}

Responsible for test facility function recheck. Responsible for test bench performance test operation \& training.

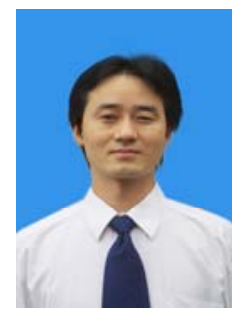

\section{Wanhu Jin, Engineer}

Responsible for design of electric power cabinet \& electric cable of the test bench.Responsible for supporting commission of the test bench. 